\begin{tabular}{|c|l|}
\hline Title & Current Status and Issues of Coworking Spaces in Japan \\
\hline Author(s) & A be, Tomokazu; Uda, Tadashi \\
\hline Citation & Discussion Paper, Series A, 302, 1-19 \\
\hline Issue Date & 2016-04 19 \\
\hline Doc URL & http://hdl.handle.net/2115/61397 \\
\hline Type & bulletin (article) \\
\hline File Information & DPA 302.pdf \\
\hline
\end{tabular}

Instructions for use 
Discussion Paper, Series A, No.2016-302

Current Status and Issues of Coworking Spaces in Japan

Tomokazu Abe and Tadashi Uda

April.2016

Graduate School of Economics \& Business Administration

Hokkaido University

Kita 9 Nishi 7, Kita-Ku, Sapporo 060-0809, JAPAN 


\title{
Current Status and Issues of Coworking Spaces in Japan
}

\author{
Tomokazu Abe and Tadashi Uda \\ Graduate School of Economics and Business Administration, Hokkaido University
}

\begin{abstract}
The purpose of this paper is to clarify the actual condition of coworking spaces in Japan, based on a questionnaire survey. A way of working called "coworking” and a place for such work called "coworking space" have been attracting attention in recent years because they may provide a more flexible work style, diverse members to interact with, and open spaces than are experienced when working in a specific company or corporate office. However, we still have not acquired the whole picture of coworking and coworking spaces because of insufficiency of the comprehensive research. Thus, we attempt to shed some light on the current status of coworking spaces in the following steps. Firstly, we review previous studies about coworking. Secondly, we will present the current status and issues of coworking spaces, based on a questionnaire survey conducted among almost all coworking spaces operating in Japan. Finally, we consider the significance of our findings, comparing with those in previous studies.
\end{abstract}

Keywords: Coworking, Coworking Space, Complete Enumeration, Management, Issues 


\section{Introduction}

The purpose of this paper is to clarify the status of the coworking spaces in Japan, based on a questionnaire survey. Specifically, of the 365 spaces, which are estimated as nearly all the operating facilities in Japan as of July 2014, the data obtained from 152 were analyzed. This paper intends to reveal and discuss the current status of management (policies, competitors, and collaborations) and its issues.

The term "coworking" refers to a "way of working in which individual workers gather in a place, share information and wisdom through communication, and create value while cooperating as needed" (Uda, 2013), and “coworking space” refers to a workspace physically shared by individuals practicing coworking.

This way of working and its spaces have been attracting attention because they may be able to provide a more flexible work style, diverse members to interact with, and open spaces than are possible for those working in a company or corporate office. Coworking spaces have been established one after another in many countries, running to approximately $7,800^{1}$ worldwide and more than 350 in Japan today. However, the current understanding of coworking and coworking spaces is insufficient.

Thus, this paper, based on data obtained in a questionnaire survey, discusses the current status of the domestic coworking space, from the perspective of the aforementioned management and issues. $^{2}$

\section{Previous Studies}

What is the reality of the coworking space? As mentioned in the introduction, coworking and/or coworking spaces are not limited to the Western world; they have steadily been spreading in Japan and other countries. However, few surveys and studies empirically reveal the current status of this phenomenon.

Although this has occurred gradually, suggestive findings have accumulated in Japan and overseas. Therefore, we review previous studies, from the perspective of the two aforementioned factors: management (Section 2.1) and issues (Section 2.2). By focusing on these points, we will be able to grasp the current status of the coworking space, utilizing relevant findings in the following questions: under what policy do they operate, with what facilities do they compete, and with what entities do they forge relationships? Further, as a result, what issues do they face?

\footnotetext{
${ }^{1}$ See the facebook page of Deskmag: (https://www.facebook.com/deskmag.coworking/photos/a.208558519173827.61310.186275991402080/1166979896 665013/?type=3\&theater). Deskmag, an online magazine about coworking, conducts the Global Coworking Survey described later.

${ }^{2}$ We focus on coworking spaces in this paper because they do not change over time as much as coworkers, allowing us to obtain basic knowledge and helping us understand the overall picture of the phenomenon of coworking.
} 


\subsection{Management}

\subsubsection{Management Policy}

According to the second survey ${ }^{3}$ conducted by the Global Coworking Survey, ${ }^{4}$ a global annual survey on the topic of coworking denoted hereafter as GCS, the entities operating coworking spaces are $80 \%$ private, $13 \% \mathrm{NPO}$, and the rest governmental. Additionally, $74 \%$ of the space managers have side businesses. Most coworking spaces, in other words, are operated by profit organizations that are not devoted entirely to the coworking space business.

Additionally, according to Spinuzzi (2012), who conducted qualitative research ${ }^{5}$ on nine coworking spaces in Austin, Texas, in the United States, the definition of the business, or the space managers' vision of the coworking space, can be summed up in these three points. A community workspace or unoffice, or federated space where is not only intended for user interaction, but also encourages formal collaboration, such as business contracts.

Furthermore, Nakamura (2013), upon sorting and analyzing the operating status of twenty-three domestic coworking spaces, attempted to categorize the working spaces along two axes: operational purposes (goal/community-focused) and utilization method (drop-in/tenant-oriented). It has become apparent, as a result, that coworking spaces have been evolving from a drop-in or community-focused inclination, to one that is tenant or goal-oriented.

Among other research, Hanibuchi (2014) attempted to grasp the realities of workspace management and utilization based on qualitative research of the space manager, and quantitative and qualitative research of the user. ${ }^{6}$ Consequently, various points were clarified regarding space management. They include, for example, that the space managers emphasize community formation and member diversity; compared to the opening, they are face difficulty in management; and coworking spaces in rural areas are more conscious of maintaining a relationship with local government, compared to urban areas.

\subsubsection{Competitor}

According to the second GCS survey, the coworking space's largest competitor is the home office. Specifically, while $58 \%$ of users - over a majority - have changed their workplace from home to a coworking space, the ratio of transition from corporate offices is $22 \%$, and even smaller for other categories. Additionally, specific to the coworking space, it has been shown that there are approximately 5.3 competitors in the same city. Interestingly, a coworking space that is largely dominant in any given city has also tended to demonstrate a deficit double the amount of average coworking space. Regions with a large number of coworking spaces tend to have higher demand,

\footnotetext{
3 The second survey was conducted between October and November 2011, and data was collected from more than 1,500 people across 52 countries.

4 The GCS has been conducted annually since 2010. Its purpose is to elucidate coworking spaces and their users, space managers, and potential users.

5 Specifically, interviews were conducted with 16 operators and 17 users.

${ }^{6}$ Specifically, an interview was conducted with 11 operators (breakdown: 5 from Nagoya-shi, 3 from Tokyo special wards, and 3 from other regional cities), a questionnaire survey (99 responses) of users at 5 coworking spaces (breakdown: 2 spaces in Nagoya-shi, 1 in Tokyo special wards, 2 in other regional cities), and interviews of 5 users (Nagoya-shi) were administered.
} 
and a deeper understanding of the concept of coworking.

\subsubsection{Collaboration}

According to the second GCS survey, while $83 \%$ of the coworking spaces interact with other coworking spaces at a regional/local level, $10 \%$ do not interact at all. In other words, most coworking spaces maintain ties with other coworking spaces in varying degrees.

Additionally, according to the Coworking Wiki ${ }^{7}$ more than 450 spaces globally have entered the Coworking Visa as of November 2015. According to coworking coop, ${ }^{8} 49$ coworking spaces in Japan have entered the domestic version of the Coworking Visa, Coworking Visa.jp. ${ }^{9}$ Coworking Visa is a program started in the United States in August 2008 to encourage the mutual use of, and information exchange between, coworking spaces. ${ }^{10}$ Specifically, when a user signs up for a monthly membership with a given facility, he or she receives preferential services to another space entering this network, for example, free usage or several days' access at a discounted fee.

GCS and the Coworking Visa illustrate the current status of ties between coworking spaces, but data has also accumulated regarding the relationship between a coworking space and an entity other than a coworking space. ${ }^{11}$ For example, Hanibuchi (2014) clarifies, based on interviews with space managers, that they consider involvement with their local community, and, in rural areas, are particularly conscious of their relationship with the local government.

\subsection{Issues}

According to the second GCS survey, less than $40 \%$ of coworking spaces have turned a profit. Categorized by size, $56 \%$ of spaces with less than 10 seats fall into the red and $25 \%$ make a profit, while $70 \%$ of spaces with 50 or more seats make a profit and only $20 \%$ are in the red. Categorized by region, half of the coworking spaces in the United States are making a profit, while this number in Europe is only at $30 \%$; the number of coworking spaces reporting a loss is larger on a relative basis. According to the first GCS survey, ${ }^{12}$ European coworking spaces have nearly 30\% fewer desks compared with their counterparts in the United States, and are considered relatively smaller. It can be inferred from these results that smaller spaces are faced with the issue of maintaining or

\footnotetext{
${ }^{7}$ Coworking Wiki is a resource on the Internet for people involved in, or are who interested in, coworking. For more information, refer to the Coworking Wiki page (http://wiki.coworking.org/w/page/16583831/FrontPage) (accessed 2015.11.20).

8 The coworking coop is an association established to aid coworkers. It was launched in August 2012 by Tomio Ito, the Cahootz representative, and others.

${ }^{9}$ CoworkingVisa.jp launched in May 2012. For a list of member spaces, refer to the search page within the coworking cooperative website

(http://coworking.coop/index.php/visa/visasearch/) (accessed 2015.11.20).

10 Refer to the Deskmag article from September 2, 2013

(http://www.deskmag.com/en/the-history-of-coworking-spaces-in-a-timeline/2) (accessed 2015.11.20).

11 Specific examples include La Fonderie, a local government-affiliated organization in Paris, and Sapporo

Coworking Supporters, an industry-government-university cooperative in Hokkaido, which has supported and promoted coworking spaces through such activities as coworking space visits, event planning, and relationship building between various entities. (For further detail regarding each activity, refer to Deskmag's article from January 18,2013

(http://www.deskmag.com/en/public-support-of-coworking-spaces-the-example-of-france-la-cantine-mutinerie-676) (accessed 2015.11.20), or Kaihatsu Koho (Hokkaido Development Association) No. 588, pp. 15-16).

12 The first survey was carried out in October 2010, and collected data from 661 people across 24 countries.
} 
improving profitability.

Additionally, according to Spinuzzi (2012), space managers expected users to share a background with them; however, in reality, the users had diverse capabilities and careers in a variety of fields. It was illustrated that coworking spaces had a different outcome than expected by the space managers.

Furthermore, Nakamura (2013) noted the seven issues related to workspace management. These are as follows: the sophistication of community formation methods, ensuring the community's diversity, the construction of a revenue system, balancing location and rent, reduction of the space manager's work load and talent training, enlarging the variety of customers (user level), and setting management objectives. Aside from these, Hanibuchi (2014) demonstrated that space managers face the difficulties of establishing a community and communication lines with users, and consider the manner of space management appropriate to each location of their spaces such as Tokyo, Osaka, or other regions.

\subsection{Research Question}

This section has analyzed and reviewed previous studies regarding the coworking space. Consequently, it has been confirmed that in Japan and overseas, studies attempting an explanation of this topic have gradually amassed. However, excluding the global annual survey, GCS, most of previous studies are small-scale and limited in scope, and does not yet grasp the full picture of coworking space management. Additionally, although the GCS analysis is useful, compared to the knowledge regarding the users, the knowledge of the management organization and/or space managers is insufficient. Particularly poor knowledge exists around management policies and issues. GCS represents a global aggregate of data. Regional differences in analysis results have already been partially mentioned, but geographical characteristics, and industrial and employment structure, such as the attitude or behavior of the working people, can also vary between countries. It becomes necessary, based on these points, to gain systematic and detailed knowledge about country-specific workspace management in parallel with significant studies, such as GCS.

Thus, this paper focuses on the coworking spaces in Japan and empirically reveals under what policy they are operated, with what facilities they compete, and with what entities they forge relationships, what issues they face.

\section{Data}

This paper uses data obtained from questionnaires distributed to the space managers of domestic coworking spaces. The research was conducted via the Internet, over the 38-day period of July 28 through September 3, 2014. ${ }^{13}$

The survey respondents were selected through the following procedure. First, based on a file uploaded on Coworking JP's Facebook page, the data was updated using multiple sites. ${ }^{14}$

\footnotetext{
13 Refer to Abe and Uda (2016) for the question items.

14 We referred, in addition to Coworking.JP (https://www.facebook.com/groups/cowjp/), Coworking Space.JP (http://coworking-space.jp/) and Coworking.com (http://co-work-ing.com/) (all accessed 2015.11.20).
} 
Responses were received from 191 coworking spaces (52.3\% response rate) out of the 365 facilities estimated to be almost all operating facilities in Japan as of July 2014. Furthermore, we also decided to limit the target population to the spaces that allow drop-in (i.e., temporary) usage because we believed that, as shown in Uda (2013), the nature of coworking is best exemplified in spaces where an openness of workspace and a diversity of members are expected.

\section{Analysis Results}

This paper focuses on the management of coworking spaces and their issues. The responses in the open ended questions out of all sections were classified according to the following process: one author categorized the responses, while the other confirmed the categorization. After repeating this process several times, both authors adjusted the classifications until they were in agreement.

\subsection{Management of the Coworking Space}

\subsubsection{Management policy}

Two questions were posed regarding the management policy of the coworking space: whether there is a "focus on profitability" and whether there is a "focus on community formation." 15 Additionally, we inquired into the operation entity of the coworking space.

The coworking spaces with a "focus on profitability" had an average value of 2.68 (SD = 1.440). Eighty-three coworking spaces (54.6\%) were inclined to have no focus on profitability, higher than the 48 (31.6\%) who did. ${ }^{16}$ Therefore, it is suggested that overall, there is no strong focus on profitability. Many of the coworking spaces are profit businesses operated by private companies. Specifically, 14 were companies (9.4\%) whose activities were dedicated entirely to the coworking space business, 37 were companies (24.8\%) whose main activity was the coworking space business, and 98 were companies (65.8\%) for whom the coworking space business was a side business. ${ }^{17}$ The high ratio of companies with sources of income outside of the coworking space business potentially elucidates the lack of focus on profitability.

On the other hand, coworking spaces with a "focus on community formation" had a high average value of 4.26 ( $\mathrm{SD}=0.952$ ). Focus on community formation was demonstrated by 127 coworking spaces (83.6\%), suggesting that their space managers emphasized community formation. ${ }^{18}$

In addition to the management policy, responses were requested regarding the space manager's view of the target/ideal coworking space (multiple answers were allowed), as this was considered another factor to impact the coworking space's management. No response was received for 75 coworking spaces (49.3\%); of the remaining 77 (50.7\%), 21 spaces responded "none," and one

\footnotetext{
15 Questions were asked using a five-point Likert scale, from " 1 = completely disagree” to " 5 = completely agree."

16 We assessed the total number of responses, from " 1 = completely disagree" and " 2 = somewhat disagree," as no inclination to focus on profitability, and the total number of responses, from " 4 = somewhat agree" and " $5=$ completely agree” as an inclination to focus on profitability.

17 Regarding the 135 coworking spaces that also operate non-space businesses, the average number of non-space businesses is 1.79. The most common businesses were IT (54) and creative / design (42).

${ }^{18}$ In a questionnaire utilizing the five-point Likert scale, the sum of responses fell under " $5=$ completely agree” or “4 = somewhat agree.”
} 
responded, "do not know.” Additionally, one respondent left what we concluded was an incorrect answer. Therefore, based on the responses of the remaining 54 spaces (35.5\%), the target/ideal coworking spaces are summarized in Table 1 . As there were 70 answers from the 54 respondents, each respondent mentioned 1.3 spaces as the target or ideal on average.

When sorted in order of responses, Coworking Space 7F (Saitama-shi, Saitama) was named 14 times, Osakan Space (Osaka-shi, Osaka) 7 times, PAX Coworking (Setagaya-ku, Tokyo) 6 times, and Cahootz (Kobe-shi, Hyogo) 5 times. The primary reasons for selecting these coworking spaces include service, profitability, information dissemination, interaction between users, business concept, and management activities.

Table 1: List of target/ideal coworking spaces (Total)

\begin{tabular}{lr}
\hline Name & Frequency \\
\hline Coworking Space 7F & 14 \\
Osakan Space & 7 \\
PAX Coworking & 6 \\
Cahootz & 5 \\
Open Source Cafe, Shimokitazawa & 3 \\
Samurai Startup Island & 3 \\
CASE Shinjuku & 2 \\
Creative Lounge MOV & 2 \\
JUSO Coworking & 2 \\
Koenji Coworking Space “Kokemusazu” & 2 \\
Kyoto Research Park Machiya Studio & 2 \\
PoRTAL Shibuya & 2 \\
task-school & 2 \\
Benkyo- Café & 1 \\
Cloud Garden & 1 \\
co-ba & 70 \\
“cococi” Coworking space & 1 \\
coloco & 1 \\
Connecting The Dots & 1 \\
HanaLab & 1 \\
HUB Tokyo & 1 \\
Indy Hall & 1 \\
miTaClub & 1 \\
oinai karasuma & 1 \\
Plug and Play & 1 \\
Regus & 1 \\
SHARE & 1 \\
TANEMAKI & 1 \\
01Booster & 1 \\
\hline & 1 \\
\hline
\end{tabular}

Additionally, Table 2 illustrates all of the responses (multiple answers were allowed) of the reasons for selecting the target/ideal coworking space. The most common answer was service, with 
15 responses. Service refers to events and programs provided by coworking spaces, such as start-up support, and so forth. Other responses include frequent events, the creation of new projects, and helpful content. The next most common response was no response, with 11 responses, followed by profitability with 8 responses, business concept with 7 responses, facilities with 6, and atmosphere of the space with $6 .{ }^{19}$

All respondents (three space managers) who answered "none" as their target/ideal coworking space commented that the question applies to no candidate. For example, one responded, "There is no coworking space in the rural area that is an apt role model. Tokyo-based spaces are models for other spaces based in Tokyo, but regional spaces require space management befitting the local environment.,20

Table 2: Reasons for selecting the target/ideal coworking space (Total)

\begin{tabular}{lr}
\hline Item & Frequency \\
\hline Service & 15 \\
No response & 11 \\
Profitability & 8 \\
Business concept & 7 \\
Atmosphere of the space & 6 \\
Facility & 6 \\
Character of space manager & 4 \\
Interaction between users & 4 \\
Characteristics of users & 3 \\
Collaboration (local government) & 3 \\
Early launch & 3 \\
Information dissemination & 3 \\
Number of users & 3 \\
Cooperation between users & 2 \\
Management activities & 2 \\
Business efficiency & 1 \\
Business structure & 1 \\
Collaboration (local community) & 1 \\
Embodiment of the coworking philosophy & 1 \\
Management system & 1 \\
Membership & 1 \\
Pricing & 1 \\
Reputation & 1 \\
\hline
\end{tabular}

\footnotetext{
19 For facilities, in addition to answers referring to large spaces, or those with a large number of seats, answers referring to spatial design were also seen. Answers include, for example, a cozy space, a highly original space, or a space devised for ease of its intended use. Responses for the spatial atmosphere that indicate interactions between users were seen, such as "a salon-like space," "a genial atmosphere," and "fun and harmonious."

${ }^{20}$ As supporting evidence of these answers, a response was sent to the open space for correspondence: "Coworking spaces operate completely differently between Tokyo and local areas. Coworking spaces are a place of escape in Tokyo, while in local areas they are places to visit with intention. This is because freelancers in local areas already have a workspace secured within the home.”
} 


\subsubsection{Competitor}

What type of facilities do space managers recognize as a competitor? The 124 responses (81.6\%) were investigated, which excludes the 28 (18.4\%) who answered "no competitor in particular" (multiple answers were allowed). When sorted in order of the number of responses, rental office/shared office had 79 responses, cafe/casual restaurants had 67 responses, home/SOHO had 55 responses, and incubation facility had 51 . If many space managers felt a certain facility was a competitor, the number of responses for that item increased, as multiple answers were allowed. However, the largest number of responses to any one facility was 79 . The responses were not concentrated to any specific facility, and it can be inferred that the space manager perceives many facilities as competitor.

Further, if limited to the relationship with local coworking spaces, the average value of the "compete with neighboring spaces" is low, at 1.86 ( $\mathrm{SD}=0.970)$. Even when noting distribution, only 10 respondents (6.6\%) listed local coworking spaces as competitor. ${ }^{21}$

\subsubsection{Collaboration (Collaboration Policy)}

According to Hanibuchi (2014), coworking spaces are focused on collaboration with local/regional communities and government. Therefore, we focused on collaboration with relevant entities, and responses were sought regarding collaboration with distant spaces, local communities, other companies, local government, NPO, and public institutions. A 5-point rating scale was used for these items. Further, for responses of " $4=$ somewhat agree" and " $5=$ completely agree," answers were requested regarding the specific nature of the collaboration (multiple answers were allowed). ${ }^{22}$ The number of targets of this discussion was as follows: distant spaces, 55; local communities, 83; other companies, 70; local government, 50; NPO, 45; public institutions, $29 .^{23}$

The specific collaborative efforts with distant spaces (68 total responses) included information exchange, with 19 responses; mutual induction, with 14 responses; events, with 12 responses; and mutual use, with 11 responses. ${ }^{24}$ Responses that mention Coworking Visa.jp (6 responses) are also an example of mutual use, but this paper treats these independently, as such a nationally collaborative effort is considered noteworthy. There are 17 total responses regarding mutual use, which suggests that the coworking spaces that strongly collaborate with distant spaces not only exchange information, but also introduce users to each other or promote mutual use.

\footnotetext{
21 The questionnaire utilized a five-point Likert scale, with the sum of responses falling under " 5 = completely agree" or " 4 = somewhat agree."

22 The average value of each is 2.75 for distant spaces ( $\mathrm{SD}=1.479), 3.47$ for local communities $(\mathrm{SD}=1.297), 3.07$ for other companies (SD = 1.486), 2.63 for local government (SD = 1.500), 2.44 for NPOs (SD = 1.427), and 2.24 for public institutions ( $\mathrm{SD}=1.285)$.

23 During classification, collaboration was assumed for cases in which there is a mutual human/material interaction between coworking spaces, such as a business alliance, as well as advice offered from other entities. Responses that did not apply to these were treated as incorrect answers. Therefore, the responses mentioned below exclude the number of incorrect responses. Further, as some space managers mentioned multiple forms of collaboration, the total number of collaboration examples within each entity does not match the number of spaces to be analyzed. For example, there are 55 spaces for analysis in distant spaces. Among these, three were classified as incorrect responses. From the 52 remaining coworking spaces, 68 examples of collaboration were obtained.

${ }^{24}$ Mutual induction includes cases in which space managers visit each other's space, and mutually introduce users to the other's space. Many of the responses corresponding to events were co-hosted events.
} 
The majority of collaborative efforts with the local community (78 total responses) are comprised of events (32 responses) and community participation (21 responses). Events include the planning and management of events, and co-hosted events. Community participation points to cooperation with urban and regional development organizations, and attendance at council meetings.

The highest number of responses among collaboration with other companies (75 responses) was "events" and "business alliance," each with 22 responses. Events include events and seminars, co-hosted workshops and projects. Additionally, business alliance goes beyond the scope of joint ventures to include support for new business development, promotional activities for other companies, the creation of matching opportunities, technical collaboration, and collaboration in employment and start-ups.

Among examples of local governmental collaboration (56 responses), events, and services both topped the list, each with 15 responses. Services received include receipt of business support grants and consultation during the application process for grants/subsidies, the call for workspace utilization, and advisory from a cooperative, consisting of industry, government, and university. ${ }^{25}$ The next highest response was contracting, with 10 responses, which includes community development projects and commissioned projects from the (local) government.

The highest number of responses for collaboration with NPOs (36 responses) was events, with 15 responses. There are many co-sponsored events with NPOs, but there are also examples of coworking space staff participating in NPO-sponsored events. Venues provided for NPO activities and meetings, and business alliances each received 6 responses. ${ }^{26}$

The highest number of responses for collaboration with public institutions (31 responses) was also events, with 10 responses. Business alliances followed, with 9 responses. Business alliances include accepting interns, joint research projects with universities, and collaboration with university lectures.

\subsubsection{Collaboration (between coworking spaces)}

Responses were also requested for the top three closely associated coworking spaces, to examine the collaboration between coworking spaces, and the degree and specific nature of collaboration, as with the above categories. 66 coworking spaces (43.4\%) did not leave a response. The data suggests, in other words, that up to $40 \%$ of space managers have determined they have no noteworthy ties with other coworking spaces.

A weighted scale was used for the responses from the 86 remaining coworking spaces (56.6\%): 3 points to the number one position, 2 points to the number two position, and 3 points to the number three position. This was used to find coworking spaces with strong or a lot of ties. Figure 1 contains the score distribution, and Table 3 shows a segment of the aforementioned coworking

\footnotetext{
25 In addition to the Sapporo Coworking Supporters mentioned in Note 11, other groups, such as the Shikoku Bureau of Economy, Trade, and Industry, and the Shikoku Coworking go! go! Project Executive Committee, also fit this example.

${ }^{26}$ Business alliances include start-up support and operational support for crowdfunding.
} 
spaces. ${ }^{27}$ Coworking Space 7F, MYCAFE (Nagoya-shi, Aichi), Cowaki (Kyoto-shi, Kyoto), JUSO Coworking (Osaka-shi, Osaka), PAX Coworking, and Osakan Space are coworking spaces with strong or many ties. ${ }^{28}$ However, as illustrated in Figure 1, the coworking spaces mentioned by space managers were 99 responses. Additionally, 70 coworking spaces were distributed between 1 and 3 points, but many received only one mention from other coworking spaces; in other words, there are many cases in Japan of coworking spaces with few ties.

27 Table 3 was created with reference to Figure 1. More specifically, the items were confirmed in the order of the score, noting items in which a change was observed in the number of coworking spaces. Attention was given to the 29 coworking spaces with more than five points (after weighting).

${ }^{28}$ It should be noted that the order changes slightly when using a simple sum of the responses. However, no significant differences are observed. 
Table 3: List of strong/many ties

\begin{tabular}{lr}
\hline Name & Score \\
\hline Coworking Space 7F & 18 \\
MYCAFE & 14 \\
Coworking Space “Cowaki” in Kyoto & 11 \\
JUSO Coworking & 10 \\
PAX Coworking & 10 \\
Osakan Space & 9 \\
Cloud Garden & 8 \\
cocolin & 8 \\
Noraya & 8 \\
Open Source Cafe, Shimokitazawa & 8 \\
SAKURA WORKS at Kannai & 8 \\
Cahootz & 7 \\
Coworking space \& cafe Robust & 7 \\
co-ba & 6 \\
COWORKING SPACE ASAHIKAWA 37 & 6 \\
Coworking Space Denpakudo & 6 \\
HanaLab & 6 \\
KOIL & 6 \\
Lightningspot & 6 \\
LiTaClub & 6 \\
Beez & 5 \\
common room NAKATSU & 5 \\
mass $\times$ mass | Kannai Future Center & 5 \\
mocco & 5 \\
Social Hub Space Knower(s) & 5 \\
Socilabo & 5 \\
\hline & 5 \\
\hline
\end{tabular}

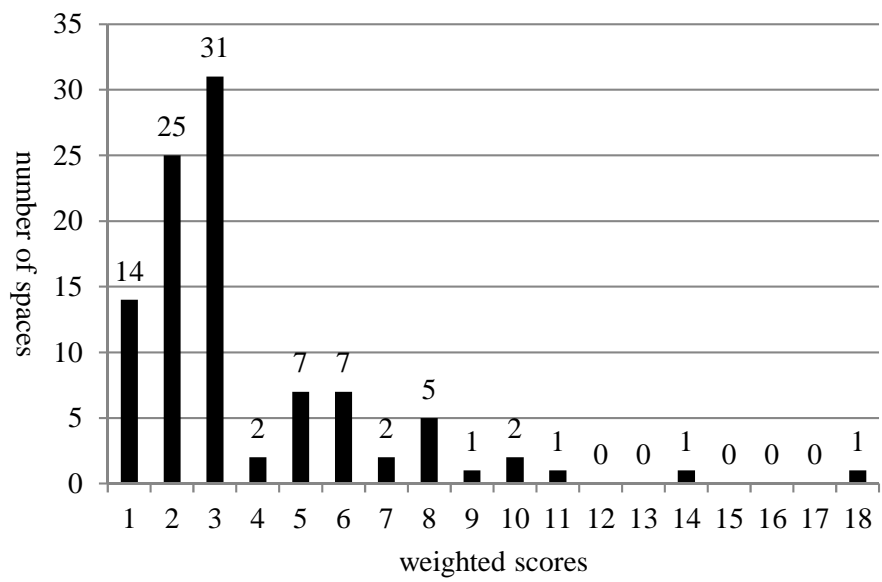

Figure 1: Distribution of weighted scores 


\subsection{Issues related to coworking space management}

This paper, in addition to management policy, competitor, and collaboration, also sought responses regarding the issues of coworking space management. Ninety-nine space managers responded (65.1\%), and because some of the respondents mentioned several issues, 162 responses, as illustrated in Table 4, exceed the number of managers who responded. ${ }^{29}$

The highest number of responses was "increase in new users," with 30 responses. The second most common answer was "increased recognition (profile)," with 17 responses. This implies a lack of recognition with potential targets.

Many responses pointed to "improvements in facilities" (14 responses) and "enrichment of events" (13 responses). ${ }^{30}$ Improvements in facilities included modifying the layout, and the adding of equipment. Enrichment of events included increasing events directed towards a potential target, information dissemination regarding event participation, and the acquisition of event organizers.

"Promoting interaction" and "increased recognition (business content)"31 each received 9 responses. "Promoting interaction" refers to the interaction among users. Several responses indicate that users only devote themselves to their work, and that interaction between users is not observed. ${ }^{32}$ Increased recognition (business content) refers to the state in which the coworking space itself is recognized, but there is insufficient knowledge about its functions and purpose. ${ }^{33}$ These two answers highlight a lack of understanding regarding coworking and coworking spaces.

Further, "increase in profit" (9 responses) and "increase in membership" (8 responses) were issues for some coworking spaces, as some expressed a lack of membership. ${ }^{34}$ Eight coworking spaces listed "increase in personnel" as an issue, and several responses noted the disadvantages from the lack of resident staff, other than the space manager. ${ }^{35}$ In other words, we note the frequency of coworking spaces attempting to secure a stable source of revenue and consistent business hours.

\footnotetext{
${ }^{29}$ Due to the exclusion of incorrect responses (3 responses), the actual number of responses is 165 .

30 Issues listed include the cramped space, inability to secure parking, fragmented space with no sense of unity, and how to separate the cafe and coworking spaces.

${ }^{31}$ Four coworking spaces mention both profile and business content recognition as issues. This suggests that the recognition of a given coworking space relies on the following independent issues: 1) the location of the space, and 2) the purpose of the space.

32 Specifically, the response was that "the space has elements that make it closer to a working space than a 'coworking' space.” A similar answer was also observed in the open space for correspondence. For example, "If anything, the space is closer to a rental space, and has not yet become a 'coworking' space."

33 Responses were observed, as in the following: "We've been told that it's difficult to perceive what can be accomplished in a coworking setting and how to utilize the space. In particular, women seem to think that there's a high barrier of entry, even for drop-ins." Another response was that "it is not immediately known what they are offering, and so it is difficult to forge an appropriate atmosphere.”

34 Other responses included a short period of time since the opening, and small membership.

35 One response mentioned that it is necessary to hire staff with the knowledge to encourage interactions between users.
} 
Table 4: Issues of coworking space management

\begin{tabular}{lr}
\hline Item & Frequency \\
\hline Increase in new users & 30 \\
Increased recognition (profile) & 17 \\
Improvements in facilities & 14 \\
Enrichment of events & 13 \\
Increased recognition (business content) & 9 \\
Increase in profit & 9 \\
Promoting interaction & 9 \\
Increase in membership & 8 \\
Increase in personnel & 8 \\
Establishing a management system & 5 \\
Expansion of services & 5 \\
Diversity in users & 3 \\
None & 3 \\
Continuity of business & 2 \\
Dissemination of etiquette rules & 2 \\
Gaining repeat users & 162 \\
Increase in drop-in users & 1 \\
Increase in unit price & 1 \\
Time management by the space manager & 1 \\
Not specified & 1 \\
Adjustment of demands among users & 1 \\
Collaboration with the local government & 1 \\
Communication with users & 1 \\
Contriving new source of income & 1 \\
Control of user layer & 1 \\
Creation of business & 1 \\
Establishment of a new facility & 1 \\
Increased user satisfaction & 1 \\
Increase in local users & 1 \\
Increase in member satisfaction & 1 \\
Increase in registered users & 1 \\
Information collection & 1 \\
Reduction in service costs & 1 \\
Trust building with the local community & 1 \\
& 1 \\
& 1 \\
\hline
\end{tabular}

\section{Examination}

\subsection{Examination of Management}

\subsubsection{Management policy}

The private sector comprised $80 \%$ of coworking spaces' operation entity in the second GCS survey, while comprising only $13 \%$ of NPOs. A direct comparison is difficult, as this paper allowed multiple responses for all applicable business areas outside of the coworking space. However, it is possible to identify trends by analyzing the actual answer, as 5 were local governmental 
organizations; it was further noted that there were 9 responses for community development and 1 response for social services among the responses in the open ended question. Even if examples of coworking spaces principally operated by local governmental and non-profit businesses were considered, this paper still has a higher proportion of privately operated spaces than the GCS survey results.

According to the second GCS survey, $74 \%$ of the space managers reported having a side business. A direct comparison is also difficult with this item, but we examine the degree of full-time operation as a proxy variable. The exclusive specialization in coworking space management is $9.4 \%$ of the total for this survey; most coworking spaces operate other businesses. Thus, the same tendency as the GCS survey is reported.

Hanibuchi (2014) noted, regarding the policy of the coworking space's community, that space managers emphasize community formation and its members' diversity. This paper also notes that many of the space managers are focused on community formation within the coworking space. Specifically, 127 spaces (83.6\%) emphasize community formation. If all domestic coworking spaces become targets of analysis, the evolution of the drop-in or community-focused inclination to a tenant or goal-oriented approach, as cited by Nakamura (2013), may not be witnessed.

Additionally, as noted in the open ended question regarding the target or ideal coworking space, it was suggested that the ideal coworking space is one with enriched events and other programs, secured profitability, and interaction between users. It is suggested that given that a portion of hosted events also promote interaction between users, the space managers focus on community formation.

\subsubsection{Competitor}

According to the second GCS survey, coworking spaces' largest competitor is the home office. On the other hand, this paper has illustrated that rental or shared offices, and cafes or casual restaurants, are also coworking spaces' competitors. There is also a tendency to discount other neighboring coworking spaces as competitor.

\subsubsection{Collaboration Policy}

Coworking Wiki and Hanibuchi (2014) outlined the current status of the Coworking Visa, and illustrated the coworking space's awareness of involvement in the local community. However, these neglected to provide attention to the collaboration between the coworking space and other entities. Therefore, this paper focused on six principal entities: distant spaces; local communities; other companies; and local government, NPO, and public institutions; and revealed concrete examples of their collaboration. Specifically, in the collaboration with distant spaces, cooperative efforts, such as information exchange, mutual induction, and mutual use contribute to service improvements in each coworking space. ${ }^{36}$ Meanwhile, among the remaining five principal entities, events and business alliances were the collaborative efforts that occurred most often. Collaboration with local

\footnotetext{
36 This paper only considered collaboration with distant spaces. Future studies intend to conduct additional surveys and examine collaborations with neighboring spaces.
} 
communities had the highest response of the six principal entities, with 83 coworking spaces reporting this as true. This is the same trend as in Hanibuchi (2014), who demonstrated that space managers emphasize collaboration with the local community. ${ }^{37}$

\subsubsection{Collaboration Among Coworking Spaces}

The second GCS survey noted that $10 \%$ of coworking spaces do not interact with other spaces. Uda and Abe (2015) found 76 coworking spaces (50.0\%) did not collaborate with neighboring coworking spaces, and 66 coworking spaces (43.4\%) did not collaborate with distant spaces. ${ }^{38}$

Furthermore, regarding the association between coworking spaces noted in this paper, it was illustrated that 66 space managers (43.4\%) were under the impression that there is no association between coworking spaces. The analysis of the open ended question also reveals the trend shown in Uda and Abe (2015). The Japanese spaces examined in this paper, in other words, have less interaction among coworking spaces compared to the coworking spaces examined in the GCS survey.

Further, the following can be inferred from the collaboration between coworking spaces, as shown in Table 3: In Japan, there is no single core coworking space that has links to many spaces, or a strong link with a particular space; rather, multiple networks are comprised of small groups of coworking spaces. ${ }^{39}$

\subsection{Examination of Managerial Issues}

Uda and Abe (2015) suggested that space managers are dissatisfied with the current status of coworking space management. Specifically, regarding the question, "I’m satisfied with the current state of the space that I operate.” there were only 23 spaces (15.1\%) who responded as "satisfied."40 Therefore, space managers listed a variety of issues, as their responses are noted in Table 4.

The most common response was the "increase in new users," with 30 responses. This seemingly draws the same conclusion as previous research, which presented 127 space managers (83.6\%) who answered yes to the question, "I would like to increase users at the space that I operate." (Uda and Abe, 2015). ${ }^{41}$

However, only 3 respondents specifically mention "diversity in users" as an issue. Therefore, as Spinuzzi (2012) notes, it can be inferred that coworking spaces’ users possess diverse careers and capabilities. Uda and Abe (2015) noted a close approximation between the assumed user profile

\footnotetext{
${ }^{37}$ Hanibuchi (2014) also clarified that coworking spaces in rural areas are more specifically conscious of their relationship with local government. This paper noted that 50 coworking spaces were in collaboration with the local government. However, the differences were not examined between urban and rural areas. This will be a follow-up point for future research.

38 The five-point Likert scale was used for the following two questions: "We are collaborating with neighboring coworking spaces," and "We are collaborating with distant coworking spaces.” The sum is noted for coworking spaces that responded as either, " 1 = completely disagree" or " 2 = somewhat disagree."

39 The present paper, as in the second survey of GCS, did not conduct an analysis with a focus on the proximity of space, such as on regional and local levels. This could become a future task.

40 The questionnaire utilized the five-point Likert scale, and the sum of responses that fell under " $5=$ completely agree" or " 4 = somewhat agree" is noted.

41 Ibid.
} 
prior to the space's opening and the actual user. More specifically, although information technology (99 users) and creator/designers (92 users) are the primary user groups, sales/marketing (49 users), literary/writers (46 users), manufacturing (43 users), and community development (43 users) also comprise approximately $30 \%$ of coworking space users. ${ }^{42}$

Previous studies have asserted that securing revenue is also an issue facing coworking spaces. For example, according to the second GCS survey, only $40 \%$ of spaces are profitable. A similar trend is seen in Uda and Abe (2015). Only 31 coworking spaces (20.4\%) are profitable in the coworking business alone. ${ }^{43}$ However, based on the open ended question in this research, only 9 spaces cite "increase in profit" as an issue, a seemingly small number compared to the number of coworking spaces that have answered that they are profitable. However, very few respondents specialize exclusively in the coworking space business. A response was also observed in the open ended question that core members of management finance operating costs through a separate source of income. There is a possibility because of this that securing profits from the coworking business alone is not recognized as an issue. ${ }^{44}$

Issues related to community formation within the coworking space, such as "enrichment of events" (13 responses) and "promoting interaction” (9 responses) in the space, also saw a relatively high number of responses. Nakamura (2013) mentions the sophistication of community formation methods, while Hanibuchi (2014) mentions the difficulty of community building. These suggest that community formation is an issue facing the coworking space in Japan.

Space managers who listed "increase in personnel" (8 responses) and "establishing a management system” (5 responses) were also present, though a minority. The responses left in the open ended question depict various problems, such as the lack of resident staff, and closure of the coworking space due to the space manager's errands. Establishing a management system also presented issues, such as the personal management of the system by the space manager and enactment of the rules of usage. These items are equivalent to the issues cited by Nakamura (2013), such as the alleviation of the space manager's burdens, and talent training.

The issues mentioned in Hanibuchi (2014), such as the manner of space management suitable for large cities or other provinces, were not mentioned as an issue in this study. However, the response of one space manager, who responded "none" to the open ended question about the target/ideal coworking space question, suggested that cities and rural areas each have methods of coworking space management appropriately suited for each region.

While issues identical to previous studies become apparent, some issues different from prior studies, such as "increased recognition (profile)" and "improvements in facilities" have surfaced. Of the coworking spaces queried in this paper, 43 space managers (28.3\%) have had within one

\footnotetext{
42 However, Abe and Uda (2016) demonstrated a lack of diversity in user attributes (occupation); thus, attention is required in the interpretation. Focus on the proportion of users reveals the correlation coefficient between freelancers and employees to be -0.484 , and a correlation coefficient between freelancers and students of -0.353 . 43 The category, "The space generates profits on a non-consolidated basis," has a sum of responses that fell under " 5 = completely agree" or " 4 = somewhat agree" when utilizing the five-point Likert scale.

${ }^{44}$ However, factors that contribute to profitability, such as "increase in profit" (9 responses) and "increase in membership" (8 responses), are mentioned as issues. This indicates that the improvement of profitability is recognized as an important challenge.
} 
year of space management experience, and 25 spaces (16.4\%) fall within six months. If filtered for three years, the criteria fits nearly all spaces, with 143 spaces (94.1\%). Therefore, not enough experience has been accumulated in coworking space management, and space managers may attempt a trial-and-error process to elevate the space's recognition, and to achieve an optimal facility layout.

\section{Conclusion}

This paper clarified the current status of Japanese coworking space management (policies, competitors, and collaborations) and its issues, while examining these topics. Few empirical studies exist regarding coworking spaces and coworking, as previously described. This paper's findings, based on data across 152 coworking spaces in Japan, are considered to be significant, as few studies have attempted to grasp the entire picture of coworking. However, some challenges remain, and primarily those related to survey design and analytical methods.

The biggest challenge for survey design is the implementation of the user survey. For example, for GCS and Hanibuchi (2014), user data has also been collected and analyzed. Research regarding users - and not just space operators - is essential to understand the entire picture of coworking. It is also advantageous to conduct a panel survey on coworking space management and compare this with GCS findings.

The one of the challenges related to analytical methods is that this study consisted only of descriptive statistics, including analysis of the open ended questions. It is necessary to reconfigure the questionnaire and conduct additional surveys, based on findings in this paper, to achieve a comprehensive understanding of coworking space management and a way of working called coworking.

\section{Acknowledgments}

Space managers of coworking spaces across the nation allocated their valuable time to participate in the questionnaire. The results in this paper form part of research supported by Grant-in-Aid for Scientific Research (B; JSPS KAKENHI Grant Number 25285110) and Grant-in-Aid for Scientific Research (C; JSPS KAKENHI Grant Numbers 26380450 and 15K03596). We would like to take this opportunity to express our gratitude. 


\section{References}

Abe, Tomokazu, and Tadashi Uda (2016). "A Correlation Analysis of the Questionnaire Survey on Coworking Spaces in Japan,” Graduate School of Economics and Business Administration, Hokkaido University, Discussion Paper, Series A, No. 299.

Hanibuchi, Tomoya (2014). FY 2013 Special Research Report: The Current State and Potential of Collaborative Workspace in Urban Areas, Nagoya Urban Institute, Nagoya Urban Development Public Corporation (in Japanese).

Nakamura, Masaaki (2013). "Current Status and Strategies for the Coworking Space Business," Journal of the faculty of Management (Chukyo University), 22 (1 \& 2), 59-74 (in Japanese).

Spinuzzi, Clay (2012). "Working Alone Together: Coworking as Emergent Collaborative Activity,” Journal of Business and Technical Communication, 26 (4), 399-441.

Uda, Tadashi (2013). "What is Coworking? A Theoretical Study on the Concept of Coworking," Graduate School of Economics and Business Administration, Hokkaido University, Discussion Paper, Series A, No. 265.

Uda, Tadashi, and Tomokazu Abe (2015). “A Descriptive Statistics on Coworking Spaces in Japan,” Graduate School of Economics and Business Administration, Hokkaido University, Discussion Paper, Series A, No. 297. 